\title{
Information Literacy Instruction for Satellite University Students
}

Library Administration at the University of Lethbridge recently decided to explore options for providing information literacy instruction to students enrolled in the introductory academic writing course at the University's two satellite locations. This was motivated both by fiscal restraints as well as a desire to explore using information technology to provide enhanced library service to satellite campus students on an ongoing basis. After conducting an extensive literature review, a scan of practices for distance learning in libraries at other institutions, and exploring a variety of technological options, it was decided that information literacy sessions would be provided at these campuses via a live Skype video call. In the Fall of 2010, this was attempted with five sections of Writing 1000. Despite some technical challenges, this pilot was determined to be largely successful. In the Spring 2011 term a similar project was undertaken with some minor modifications based on the lessons learned in the previous term. In addition, students were provided with additional information literacy instruction via online tutorials that were developed for Writing 1000 students at all three locations, including the main campus. This paper provides a broad outline of the current climate in adult information literacy for distance education students according to our research. The successes, challenges and lessons learned from our pilot project are also shared.

\section{Information Literacy}

The Association of College and Research Libraries (ACRL) defines information literacy as "a set of abilities requiring individuals to recognize when information is needed and have the ability to locate, evaluate, and use effectively the needed information" (2000, p. 2). The skills associated 
with information literacy are widely recognized both inside and outside the library profession as essential. While the role of the librarian was once associated with providing access to information, in the information age, at least in developed countries, access to information is becoming less of an issue. Librarians now have an important role to play in assisting patrons with sorting through and evaluating vast quantities of information that exist well beyond the physical boundaries of the library. "(A)s librarians we recognize that providing access to information is only the first part of the process. Knowing how to interpret, analyze and use information in an ethical manner is vital if we are to transform people's ability to learn and thrive in the digital world" (Secker, 2007, p. 2).

Gibson (2008) accounts for the existing information literacy gap as a result of students' expectations for instant information access which results in a willingness to settle for "less than optimal” information (2008, p. 12). “[S]o-called 'digital natives' are growing in confidence that 'Googling' will suffice” (Secker, 2007). Academic libraries and librarians have an important role to play in ensuring that post-secondary students develop the level of information literacy required to be successful in their academic careers and beyond. The description of the role of the librarian in information literacy is constantly evolving. There is mounting evidence to support the notion that librarians need to be more closely integrated into the teaching and learning process. While currently librarian involvement usually occurs on a piecemeal basis depending on the initiative and faculty relationships of individual librarians, there is certainly a place for making this a part of institutional policy and under the strategic direction of senior management (Newton, 2007). 


\section{Distance Education and Adult Learners}

In addition to providing effective information literacy instruction for on-campus students, librarians are increasingly being called upon to participate in distance delivery of services and instruction. According to Barnhart and Stanfield, “(i)n the past 15 years... distance learners have become an ever more important constituency in higher education...” (p.59). When developing services for any group of people, it is important to be familiar with the characteristics and requirements of that group in order to effectively meet their needs. As Whitehurst and Willis (2009) explain, “(s)tudents who participate in distance education are typically older, nontraditional students with unique characteristics who need special services provided by their university library in order to obtain an education equal to the on-campus counterparts" (p. 20). Except to say that they are often more diverse than on-campus students, the characteristics of offcampus learners at any given institution is often not well documented, and as such we must rely on overall broad trends to try to develop an understanding of these students (Newton, 2007).

Just as technology has changed the work of librarians, people in many vocations have been called upon to engage in ongoing learning in order to continue to be effective in their chosen work. While much learning occurs on the job or through targeted professional development training, there has been a significant increase in the number of older individuals seeking postsecondary education (Wilson, 1994). According to a recent report by the Association of Universities and Colleges of Canada (2007), it is "reasonable to assume that the growth of the knowledge-based economy and the labour market demand it generates for highly skilled and talented graduates will continue to influence university participation rates.” (p. 31). This demand 
for university graduates will likely lead to an ongoing increase in university participation by older students. This same report also indicates that older students will make up a more significant proportion of students by 2016. Due to the restrictions of jobs and family, many of these individuals are unable to return to school full time or relocate to attend an educational institution. Fortunately, technological evolution has also made it easier to provide education to learners in remote locations. The technological capacity combined with the high demand for online learning has resulted in an explosive growth in the development of online programs (Newton, 2007; Raraigh-Hopper, J., 2009; Reid, 2009; Whitehurst and Willis, 2009).

As much as adults may be eager to participate in furthering their education, work and family pressures may compete for their time and attention. Research into working adult students has identified common complaints about high stress levels and students finding it difficult to make time to manage all of their responsibilities (Arthur and Tait, 2004; Reid, 2009). In addition, the task of finding and evaluating information can be particularly challenging for adult students who are returning to studies after being in the workforce for some time. Their age, remoteness from the campus, and long absence from the educational system may all contribute to the fact that many distance students are not as familiar as their on-campus counterparts with emergent technology. This requires libraries to rethink the way they serve patrons to ensure that students are able to access library resources regardless of their physical location. Many of the factors that contribute to their success such as family support, workplace rewards and a general love for learning are beyond the ability of the educational institution to control. Other factors, however, can certainly be considered in library instruction delivery which may contribute to information retention and student success. Central to these delivery methods is understanding some of the 
core tenets of adult education (Veal, 2000). These include the method of delivery which, if done online, creates flexibility. Another vital consideration is ensuring that information literacy instruction has clear purposes and objectives which are closely tied to course assessment. In other words, students pressed for time are more likely to be engaged in and retain library instruction if its immediate usefulness in helping to successfully complete course assignments is clear to them. Unlike with children, and even young adults, adult learning is based on prior knowledge. Rather than transmitting knowledge, learning processes are often emphasized in successful adult education programs (Veal, 2000; Wilson, 1994). As such, library instruction should focus on information literacy skills as vital to an individual's life-long learning cycle.

The Association of College and Research Libraries (ACRL) has had guidelines in place since 1963 to ensure "the delivery of equivalent library services and information resources to college and university students, faculty, and other personnel in remote settings" (ACRL, 2008). The growth of distance education programs led to the conversion of these guidelines to standards in 2008. These standards provide a useful guidepost for librarians in determining how best to provide services and support to distance learners. They acknowledge the unique characteristics of distance students that should be addressed in providing library services, and emphasize the importance of having dedicated personnel and programs to meet these needs. Several provisions relate specifically to the delivery of information literacy instruction and support. Specifically, the standards indicate that " $(\mathrm{t})$ he library must provide information literacy instruction programs to the distance learning community in accordance with the ACRL Information Literacy Competency Standards for Higher Education” (ACRL, 2008). In addition, libraries must sufficiently promote the services available to distance students, and provide adequate service 
hours. Unfortunately many librarians report a lack of time and adequate channels through which to provide the level of support to distance students that they would like to make available (Newton, 2007).

\section{Does the Method of IL Instruction Matter?}

The ACRL Standards for Distance Learning indicate that instructional services should be provided by academic libraries in "formats accessible to the greatest number of people" but they provide no indication of a preferred format (ACRL, 2008). The information science literature is rife with examples of how university and college libraries have attempted to reach out to distance students, and much debate has occurred over whether the method of instruction matters when teaching information literacy skills. Numerous institutions have experimented with face-to-face, online, and blended forms of instruction and there seems to be no common or definitive conclusion; one can easily find examples to support both sides of the debate. (Adolphus, 2009; Anderson and May, 2010; Burkhardt et al., 2008; Herring et al., 2009; Hines, 2008; Holman, 2000; Jayne, 2000: Reid, 2009). One reason for this is that online instruction is still relatively new and instructors are still experimenting, developing best practices and discovering the relative merits and drawbacks (Reid, 2009). At this point, not enough evaluation has been done on how users interact with tools and how effective they are (Newton, 2008). In addition, it is difficult to control for external influencing factors such as whether students self-select the method of instruction, what year of studies students are in, how comfortable online students are with using technology, the teaching style of the instructor, the individual efforts of librarians, and so on. Jayne (2000) argues that the only sure way to reach all students is to provide services in as many formats as possible. While multiple approaches might be ideal, time and resources are not 
always available to provide every kind of service imaginable. Instead, one must look at the relative merits of each and apply these to one's given situation while keeping in mind that sound pedagogy should drive the use of technology, and not the other way around.

When possible, it is ideal to be able to provide support to distance students both in person and online. However, the many advantages of online information literacy instruction and library support are increasingly making it a more attractive option. Anderson and May (2010) conducted a study comparing the retention of information literacy skills of a group of first year college students when they were given instruction either face-to-face, online only, or in a blended format and concluded, based on student scores on pre- and post-tests, that the method of instruction does not influence students' retention of IL skills. From the students' perspective, online IL tutorials are attractive because they offer flexibility; they can be accessed at any time and paused or repeated as desired (Pastula, 2010; Reid, 2009). Many distance students choose distance education precisely for its flexibility and as such, support services should offer the same degree of flexibility as much as possible. Once developed, these tools can also be used by on-campus students as well, who increasingly demand independent access to resources (Newton, 2008). The wide variety of media and instructional approaches that can be employed when developing online learning tools may also enhance the instructor's ability to reach different learning styles. (Adolphus, 2009). For some types of learners, online course delivery allows them to flourish. When online discussion forums are used they allow more time for individuals to think before responding to questions which may lead to more thoughtful answers, increased participation, and richer, more prolonged discussions (Reid, 2009). From the instructor or librarian perspective 
online courses are appealing because once developed, they can be used repeatedly and are easy to update (Pastula, 2010).

Of course, online delivery of information literacy is not without its challenges. First of all, modern technology can be costly and delivering instruction this way requires expenditures on software, staff training and technical support for users. If technological barriers lie in the way of access to learning materials, students are unlikely to access and benefit from the tools. As such, when selecting software, student access to and familiarity with technology must be considered. In this sense it is preferable to choose technology options that are mainstream or easy to integrate with the technology to which most students will have access (Pastula, 2010). While the technology costs might be balanced with savings in travel costs if librarians are not going out to meet with distance students in person, there is also a time cost. At the outset, developing online information literacy tools is very time-consuming. In addition, where there is an online discussion component, monitoring discussions can also take a great deal of time (Reid, 2009); program success and growth will in turn put even greater demands on time.

Of course, "face to face interaction is the most noticeable missing feature from online instruction" (Pastula, 2010, p.82). Reid (2009) notes that the lack of live, face-to-face interaction makes it impossible to read students' faces and body language for comprehension or to modify instruction for a particular audience In addition students are not able to communicate directly with instructional librarians and get immediate assistance (Barnhart and Stanfield, 2011). Whitehurst and Willis (2009) argue that distance students often prefer human contact when they need to learn about new resources, and technology and online instruction simply cannot provide 
the same level of human interaction that can be provided in person. This is particularly important given that online learning requires more self-direction on the part of students. Murphy and Crosser (2010) outline some abysmal statistics in terms of student retention and success among distance students which they attribute to poor self-regulation or a lack of learning strategies.

The only real conclusion that can be drawn from this debate is that for better or worse, online delivery of course content does change the nature of the class, and that whatever approach is taken at a given institution should be based on an in-depth understanding of that particular population and a careful assessment of the available tools in an attempt to provide the best service possible.

\section{Choosing the Right Technology}

If information literacy instruction and library reference services are to be provided using technological solutions, care must be taken in choosing the delivery mechanism. Ultimately there are two key considerations to bear in mind. First is realizing that we cannot simply imitate face to face classroom instruction in an online environment and expect it to be effective (Pollack, 1998). This means determining in advance exactly what type of material is to be presented and in what format, and then selecting the technology that meets the method of instruction. The second, related consideration is to underscore all instructional technology with good pedagogy. As Oud points out: “(c)ognitive psychologists have done a large amount of research on the effective use of multimedia in learning. Much of this research looks into how people process information effectively... Implications for instruction include the need to be aware of the limits of student capacities for information processing" (2009, p.165). There are limits, for example on how much 
a student can learn and absorb from a single session of an online video. There are a whole range of possible methods of delivery and software packages available for delivering educational content. As much as possible, the technology should match the intended learning objectives.

An environmental scan of other universities in western Canada demonstrated some of the choices available and the different ways that they might be employed. The University of Calgary has developed some brief, subject-specific online tutorials for their students. In addition, Elluminate is used with online students to conduct webinars in real time (Alix Hayden, personal communication, March 5, 2010). These sessions are also recorded for students who cannot be present for the live sessions to watch later. The University of British Columbia uses a combination of approaches. Those dealing with mid-career audiences prefer to use teleconference technology with distance students, having found that these students prefer a less hi-tech approach (LeeAnn Bryant, personal communication, March 6, 2010). Others have experimented with WIMBA, another web conferencing software.

Another potential web conferencing-type tool is Skype. Founded in 2003, Skype is a popular, free, web-based communication application (Booth, 2008). While this option did not arise during our initial literature review or environmental scan, it was later brought to our attention as a viable option. One common use of Skype discussed in the literature is to bring authors in touch with their far-flung readers. Messner (2010) details numerous examples of schools hosting author visits via Skype. Despite occasional technology glitches and some individual preference for faceto-face meetings, both students and authors have embraced this affordable and convenient method of communication. Publishers are also starting to experiment with Skype to allow 
authors to "visit" bookstores as a way of saving travel costs (Rosen, 2009). While these are not library applications, they are examples of ways that an individual can present to a large audience at a distance using Skype. Ohio University librarian Char Booth has used Skype both to deliver a conference presentation to colleagues across the country (Signorelli, 2008) and to provide live reference services to patrons via a Skype kiosk in the library (Booth, 2008).As with other factors, decisions about the choice of technology have to be made at a local level, and there is no onesize-fits-all solution. In reality, many technology choices are made outside of the realm of the library and what is used is based on what is currently available and supported by an institution's information technology department.

\section{Collaboration}

Perhaps even more important than the format or delivery method of library instruction is the overall strategy. Library instruction in the post-secondary environment has often been criticized for not including a critical thinking component (Anderson and May, 2010; Newton, 2007). This is largely because it is often taught to students in the form of a brief "one-shot" library instruction session with limited faculty collaboration. Not only is this not an ideal method for effective learning and instruction, it does not facilitate effective assessment of student learning (Anderson and May, 2010). Collaboration with faculty and integration into course work is vital to success irrespective of the location of IL delivery. (Anderson and May, 2010; Newton, 2007;

Owens and Bozeman, 2009; Raraigh-Hopper, J. 2009; Whitehurst and Willis, 2009). As Anderson and May (2010) so aptly put it: "The role of the librarian is to provide generic information skills that focus on the process of gathering and evaluating information across disciplines, while the role of the faculty is to provide discipline-specific skills that illustrates the 
connection between evaluating content information and validity of evidence that is tied to a particular discipline" (p.496). In order for it to receive greater emphasis, the librarian's contributions must be highly valued by the course instructor and the students as relevant and important.

Without cooperation from course instructors it becomes extremely difficult, if not impossible, for librarians to access distance students. In an ideal situation, librarians would be involved in course design to provide an information literacy perspective to content delivery (Newton, 2007). At a minimum it is up to faculty to require or at least encourage their students to use library resources for their course work, as otherwise students are unlikely to seek them out (Owens and Bozeman, 2009). This is especially true for distance students when the library has no physical presence. Librarians can facilitate this process by making information about what resources are available to distance students readily available to both students and instructors (Caspers, 2000). No matter how useful the tools available to distance students, if they are unused because they are unknown, the library has not met its obligations (Caspers, 2000). Unfortunately librarian involvement is frequently marginal, and librarians report a sense of not being taken seriously or seen as having an important role to play by their academic colleagues (Newton, 2007). Faculty do not always recognize the importance of library instruction and even when they do, the pressures of covering course curriculum often makes them hesitant to give up class time. Where successful collaboration exists, it seems to depend largely on successful outreach and relationship building on the part of the individual librarian. This is done both through personal interactions with faculty as well as being visible on campus by serving on committees (especially those related to curriculum development and education). 


\section{The University of Lethbridge Case}

All of these issues: information literacy, adult education, distance learning, and collaboration, among others, are being grappled with by the University of Lethbridge Library. The above literature review and environmental scan informed our internal discussions as we attempted to innovate and adapt to changing technologies while providing quality service to students in a variety of geographic locations.

\section{The University of Lethbridge Satellite Campuses}

The University of Lethbridge ( $\mathrm{U}$ of $\mathrm{L}$ ) is located in Lethbridge, Alberta, a city of around 84000 people located in southern Alberta. The U of L offers undergraduate and graduate programs in education, fine arts, health sciences, humanities, management, nursing, sciences, and social sciences, leading to academic degrees at the Bachelor, Masters, and Doctoral levels. There are over 8000 students currently enrolled in 150 programs across 6 faculties (University of Lethbridge, 2010a). As of the fall 2010 semester, just over 1000 of the University of Lethbridge's undergraduate students were enrolled at one of two satellite campuses: 663 students in Calgary, which is located approximately $200 \mathrm{~km}$ from Lethbridge, and another 388 in Edmonton, which is a distance of more than $500 \mathrm{~km}$ from Lethbridge (Institutional Analysis, University of Lethbridge, 2011). Both Edmonton and Calgary are large cities with more than one university located in each of them; however, in 1996 the University of Lethbridge opened campuses in these cities to offer a unique opportunity for working adults to complete undergraduate degrees and certificate studies in Management through courses offered exclusively in the evenings and on weekends. When the satellite campuses were first opened, it was believed that they would remain small and probably only exist for a short period of time (M. 
Tedesco, personal communication, January 28, 2011). Instead, unanticipated program demand has led to rapid growth of the campuses. While the actual instruction of these programs occurs mostly in person (with some blended learning options), the University of Lethbridge Library, whose only branch is on the main campus, provides materials and services from a distance.

The students at the U of L's satellite campuses largely fit the profile of distance students as outlined in the literature review. While the average age of undergraduate students enrolled at the main campus is 23 , the satellite campus students are slightly older, with an average age of 26 in Calgary and 28 in Edmonton (Institutional Analysis, University of Lethbridge, 2011). Whereas almost half of newly enrolled students at the main campus enter their programs directly out of high school, most satellite campus students enter their programs after completing a diploma or at least some post-secondary studies at another institution. While data is not collected about how many of them are currently employed full-time or part-time, given that the program is designed for the working professional and other daytime programs exist in the same city it is largely assumed that most, if not all, of them have other work or family responsibilities. Based on what is known about our satellite campus students, many of the principles of adult education can be applied to program planning for them.

\section{Services Provided to Satellite Campus Students at the University of Lethbridge}

The University Library's mission is to "advance the scholarly research and creative endeavors of the University of Lethbridge" (University of Lethbridge Library, 2009). It offers instructional programs, services, and information resources aimed at cultivating information literacy and independent learning. At the same time, like other academic libraries, the $\mathrm{U}$ of $\mathrm{L}$ library is 
endeavouring to incorporate new technologies and keep up with trends in providing services for in-person patrons. We are also seeking to discover the best approaches to provide services and support for remote students.

As much as possible, the $U$ of L Library attempts to provide equivalent access to library collections to distance students. Like their on-campus counterparts, student ID cards are provided to all students at the satellite campus offices. This card serves as a student's library card at the U of L Library. Students at the Calgary and Edmonton locations can request materials from the main campus library which are sent to the satellite campus office for them to pick up. To allow for transportation time in each direction distance students are given loans of 6 weeks on items from the main collection, compared to 3 week loans allowed for on-campus students. All online and electronic resources, including a large collection of electronic books and databases, can be accessed by distance students by logging in to the U of L library system. Students are also able to request materials unavailable from the $\mathrm{U}$ of L Library through interlibrary loan, which are also delivered to the satellite campus office for them (or where possible, such as in the case of electronic journal articles, are emailed directly to the student). Satellite campus students are also encouraged to apply for The Alberta Library Card (TAL) from the campus office. This card gives students borrowing privileges at most publicly-funded libraries in the province, including university, college and public libraries located in their home city. Their U of L Library privileges also allow them to obtain a COPPUL (Council of Prairie and Pacific University Libraries) card which gives them borrowing privileges at other universities in western Canada which are often more generous than they will receive with the TAL card. 
Library reference services are also made available to satellite campus students. The library website includes numerous resource guides on a variety of subjects ranging from help with citations to subject-specific research guides. A toll-free telephone located at the library reference desk on the main campus is dedicated to receiving reference calls from satellite campus students. In addition, students can receive assistance from librarians by filling out an online form, text messaging, or instant messaging. All of the services for satellite campus students are outlined in detail on the library's website and are linked directly off the main page. Nonetheless, anecdotal evidence indicates that many distance students do not seem to be fully aware of the services available to them; where usage data is available, these services seem to be largely underutilised. Many courses offered at the satellite campuses choose not to use course management systems, and those that do have not created links specifically advising students of their library privileges.

On the main campus, librarians are available to visit classes to provide in-class instruction in information literacy and other library-related skills. Over the past decade in particular, the dedicated information literacy librarian has worked hard to develop relationships with instructors across campus, especially those in the academic writing program. This has been done by building personal relationships with faculty, involvement in campus-wide committees and events, and demonstrating the exact relevance of library research skills to the learning outcomes of academic writing courses. While this librarian is currently on study leave, her efforts to create an environment of collaboration, as outlined by Owens and Bozeman (2009), have made the current project possible. 
Writing 1000, or "Introduction to Academic Writing", is a 3-credit hour introductory course in academic writing "designed to develop skills in critical reading and writing at the university level. The course includes the critical reading of assigned texts and an introduction to expository writing, including description, analysis, persuasion and other strategies of academic discourse" (University of Lethbridge, 2010b, p.441). This course is completed by most students in the Faculty of Management and is also taken by students in many other faculties. It has become accepted practice, supported by the head of the academic writing program, for a librarian to visit each section of Writing 1000 at least once per semester to introduce students to finding and evaluating key library resources to support the successful completion of the course's major research paper. Both students and instructors have come to value the importance of this face-toface interaction.

Until the fall 2010 semester, librarians from the main campus traveled to Calgary and Edmonton to meet with the Writing 1000 classes held there. On the satellite campuses this visit had the added value of providing an opportunity to promote the library services available to the students in these remote locations, and to create a personal connection between the students and the library. Over time, satellite campus instructors have become more familiar with library personnel and services as well. One challenge the U of L Library faces is that many of the instructors at the satellite campuses are sessional, hired term-by-term based on need, and as such there is a reduced likelihood of staff stability over time. This results in constantly rebuilding relationships and educating new instructors about library services and resources. 
Providing this in-person information literacy instructional service to satellite campuses is not easy. As mentioned, the campuses are each located several hundred kilometres from Lethbridge which makes it both costly and time consuming for librarians to travel to them. In addition, given the nature of course delivery on evenings and weekends it is conceivable that in order to meet with each Writing 1000 section, a librarian may need to be physically present in each satellite campus city for up to a week at a time. While it is the intention of the library to provide distance students equitable service to on-campus students, fiscal realities have made it increasingly challenging as the number of full-time librarians has been reduced and travel budgets have been cut, at the same time that the overall campus enrolment is growing. These financial and logistical constraints are not unique to the $\mathrm{U}$ of $\mathrm{L}$ and have been cited by other post-secondary institutions as a barrier to fully meeting their commitment to distance students (Wilson, 1994). Fortunately, new information and communication technologies are providing alternative modes of meeting these commitments. The $\mathrm{U}$ of $\mathrm{L}$ is not unlike many other universities, delivering more and more class content online - both to users on-campus and off. The University's Curriculum ReDevelopment Centre (CRDC) has taken the lead in training users and providing the technology to faculty. In September 2010 a new model of information literacy instruction delivery was implemented for the $\mathrm{U}$ of $\mathrm{L}$ involving the use of technology rather than the physical presence of a librarian.

\section{Virtual Delivery of Information Literacy}

As most of the satellite campus students are enrolled in the Faculty of Management, in June 2009 library administration charged the Management Liaison Librarian with the task of exploring options for providing information literacy support for the satellite campuses using a virtual 
approach. Later on in the process, the library intern was brought in to the project to conduct additional research and act in a supporting role. In addition to conducting a literature review and environmental scan, one of the important areas of investigation was to determine what technologies would best support the desired outcomes. While the cost of software and hardware were factors, ease of use for both the librarians and instructors and the availability of in-house expertise and support were also considered.

It was decided that the need to have a personal connection with our satellite students was still a high priority. The librarians who had traveled to the satellite campuses to deliver these sessions in the past reported that both the students and the instructors very much appreciated the time, effort, and personal touch made in traveling to them to ensure their comfort with the library. Software that would allow instruction to be delivered in real-time, albeit remotely, was identified as a priority as it would maintain the live, in-person atmosphere. Other librarians have identified this as an important consideration as well (Barnhart and Stanfield, 2011). Delivering the class 'live' would also ensure that the students would attend, would allow the librarian to adjust the pace of the lesson as needed, and it would allow students to ask questions as they arose. For this reason, software that could be used to only pre-record instruction sessions, such as Camtasia, were eliminated from consideration.

A further consideration was the desire to conduct instruction sessions with the students located in a computer lab so they could follow along with the demonstrations, and work on practice worksheets during the session. While initially videoconferencing the class seemed like an ideal solution, the computer labs available in Edmonton and Calgary were not equipped with 
videoconferencing equipment, and as such this was not an option. The next consideration was to use webinar software. Initially, based on the environmental scan and conversations held with other libraries delivering distance information literacy classes, Elluminate was identified as the preferred choice for conducting webinars; however, upon consultation with the CRDC, they initially recommended Adobe Connect Pro (a similar product to Elluminate) as a viable alternative to which the $\mathrm{U}$ of $\mathrm{L}$ already had a site license for. The main features desired were the ability for students to see as well as hear the librarian, and the ability to share the librarian's desktop in order to show a PowerPoint presentation as well as perform demonstrations on how to use library resources such as the library catalogue and databases. It was also desired that both the satellite students and instructors be able to speak to and ask questions of the librarian. After further consultation with the CRDC, they recommended Skype rather than the Adobe product to conduct video calls between the librarian at the main campus and the students and instructors at the satellite campuses. They suggested that Skype possessed all of the looked-for features while arguably being easier to use than Adobe Connect Pro. This simplicity was key, as there was no way of knowing the technical skills or abilities of the instructors at the remote locations, many of whom were wary of using technology in their classes. Skype was also appealing for its potential to later conduct one-on-one research consultations with distance students.

IT support staff at each of the two satellite campuses downloaded Skype onto the instructor's classroom computers at their locations, and the library purchased and provided them with a webcams and microphones. Two cameras and microphones were also purchased for use by the two librarians involved with the project; a fortunate outcome of this was that they could initially test the software and hardware on-site before conducting live sessions with students. Test 
connections were also made with both campuses before the actual classes. For the most part, the test sessions were successful. We had clear connections and were able to share our screens with no difficulty. The pressure to perform was made especially intense as the instructors in Calgary and Edmonton were extremely disappointed when they were told that librarians would no longer be traveling to deliver the information literacy sessions in person, as they had valued this service highly in the past.

After successful testing, we prepared presentations to be delivered live to students. The instruction sections sessions began with the librarian introducing herself on camera, which was projected up on the classroom screen, in order to have a face for the students to see to make them feel as much of the live presence as possible. After the introductory comments had been made, the screen was switched to screen-sharing mode. The content of these sessions was partly promotional, to introduce students to all of the library services and support available to them; and partly instructional, to provide guidance in conducting library research. Students were also given short exercises and an opportunity to practice using the library catalogue and databases in case they wanted to ask questions with the librarian present. Unfortunately, it is not possible to have picture-in-picture screen sharing capabilities in Skype, which would have been ideal so that the students could see the librarian for the entire duration of the course. One trick was to try to remember to switch back to the video camera view when addressing a question for any length of time which did not necessitate screen sharing in order to maintain that sense of personal connection. Both PowerPoint slides as well as live demonstrations of the library catalogue and databases were shared. Unfortunately, our live sessions did introduce some unanticipated challenges. 
One of the great disadvantages of online instruction as outlined by Reid (2009), is not being able to tell if students are following what is being said, if they are interested or confused. Our Skype experiment definitely had this drawback. For much of the live session the librarian was unable to see the students in the class; there were two reasons for this. The first is that when using Skype, clear screen sharing with the satellite campuses required us to maximize our Web browser or the PowerPoint presentation that we wanted to share, which meant that we were unable to see the video image of the class at the same time. While having a second monitor would have alleviated that difficulty, the second problem was that even when we were not screen-sharing, if the webcams - which had microphones embedded within them - were directed towards at the students in the class, the ambient noise in the room created feedback. This meant the cameras had to face away from the students, making it impossible for the librarians to see them if they were speaking unless they came to the front of the class to the video camera (which few of them did). In short, while the students could see the librarian, the librarian could not see the students. As such, we relied a great deal on the instructors present in the classroom to facilitate by letting us know if we needed to pause, if students needed time to practice skills, if there were questions, etc.

We also encountered a challenge with the screen-sharing function in Skype. About 45 minutes into two of the sessions, the screen-sharing feature stopped working. While we still had a clear audio and video connection to the students, they were no longer able to view anything on the librarian's end, but they could still hear us. We tried rebooting the computers, restarting Skype, and a variety of other troubleshooting techniques but these were unsuccessful in solving the 
problem. It was never determined what the problem was, as other sessions had gone smoothly for up to $2 \frac{1}{2}$ hours. One of the challenges of these classes being on evenings and weekends is a lack of on-site technical support on either end of the connection to provide backup. At this time, despite follow-up investigations, we have no clear explanation of the problem. Our best guesses are that our screen sharing was lost due to limited bandwidth, firewall issues, or a glitch in the Skype service. Fortunately, we were able to recover from this challenge. Because we had previously sent our PowerPoint slides to the instructor, the students had access to them through their learning management system. In addition, the instructor was able to open the slides and project them in the classroom. We used the web camera to enable us to view the screen that the students were seeing and speak to the slides this way. We substituted librarian-led live resource demonstrations by relying on pre-prepared screen captures demonstrating the steps involved in a database search, or by the classroom instructor conducting the demonstrations under the guidance of the librarian. Fortunately, the instructors were very good at following directions.

Despite the technical challenges we feel that this pilot project was a success. Initially, several of the instructors were hesitant about this plan. A few reported a lack of confidence in their ability to manage the technology from their end. In addition, they expressed concern about the lack of a personal connection between the students and the librarians. Yet after the Skype sessions we received a great deal of positive feedback. For example, one instructor told us that this was a very useful introduction to the library resources for her students. Prior to our session, only 5 of 23 students in her class had ever opened the library's website (D. Guichon, personal communication, October 28, 2010). She also indicated that her students felt that as long as the technology was working properly they did not have a preference between Skype and an in- 
person presentation. Another instructor expressed enthusiasm about being introduce her students to new resources that she had previously been unaware of (J. Richardson, personal communication, October 23, 2010). In fact, all of the instructors indicated that both they and their students found the sessions valuable and helpful.

We still feel that it is important to try and connect as much as possible with our satellite campus students. While pre-recorded information literacy sessions might have avoided our technical challenges, the lack of personal interaction is not a trade-off we or the classroom instructors wanted to make. Unfortunately, formal student evaluations were not collected, even though this is common practice for the librarians in the in-person sessions. It was simply overlooked, and will definitely be incorporated for future sessions - more than likely using an online survey tool.

\section{Recommendations}

\section{Institutional}

While it is clearly beyond the mandate of the library - and certainly the individual librarians this project has led us to identify several areas where the University of Lethbridge as an institution could do more to support satellite campus students. This could begin with developing a better understanding of the population of students on the satellite campuses. While there is clearly a target audience for these programs - the working adult - apart from data on age ranges, there seems to be no clear institutional understanding of the unique needs of this population. Hopefully this would lead to clearer institutional leadership in how the main campus can, and should, support the satellite campus students. 


\section{Library Level}

Once clear institutional leadership has been established, the Library's strategic plan can and should outline a clear mandate for satellite campus support. While we do a great deal, there has been no comprehensive analysis of the services provided to the Edmonton and Calgary students in recent years despite their significant growth. This should be done by looking at the broader picture of library services provided to distance students such as the document delivery services and online databases access, in addition to Writing 1000 instruction. Perhaps one reason for the lack of analysis is that there is currently no librarian designated to be responsible for off-campus students. While it is within the Management librarian's assignment of duties to support these programs, the population size of satellite students and unique challenges of working with these students calls for far more focused attention. The work of building relationships with faculty and acting on the recommendations of this pilot project will only move forward if more time can be dedicated to their success. One of the major rationales for moving to the online method of instruction is the potential for it to lead to more regular communication with students at satellite campuses. The ability for students to request one-on-one online consultations is a possibility which has been discussed but not yet implemented. As Pastula (2010) points out, this is a time-

consuming service which is not a viable alternative for information literacy instruction, but does help to create a sense of personal connection which is obviously lacking in online services. The success of this program could lead to future linkages with other courses and departments.

\section{Librarian}


The research and consideration involved in this study has made evident the importance of continued outreach by librarians to satellite students. Even if we cannot physically travel to Edmonton and Calgary it is important to keep the visibility of the library high and continue to explore opportunities to connect with students and support them. At the most basic level this mean targeted marketing strategies. While the U of L Library currently has a link on their home page outlining services provided to distance students, it may also be advisable to develop a print manual or brochure of distance library services for both students and faculty. This could be made available to all instructors, especially new hires, and located in satellite campus offices in the hopes of raising our profile among students who are less technologically savvy.

Many Web 2.0 technologies may also create opportunities to connect with distance students. It is the responsibility of librarians to stay on top of these innovations and explore ways to use them in a proactive way. While we currently offer instant messaging to all students, we could explore what entry points satellite campus students typically use for the web and try to embed our instant messaging service in more visible locations. This may, for example, involve a more visible presence in the existing course management systems. Course management systems (CMS) "provide a convenient, focused environment in which relevant library resources can be selected and organized for specific classes in an easily accessed interface” (Herring et al., 2009, p. 630). In a second phase of this project, since January 2011, all Writing 1000 students (both on-campus and distance) have been enrolled in library research modules in Blackboard. These modules, which include short instructional videos, worksheets, and quizzes covering topics from basic library catalogue searches to evaluating sources, are required assignments for Writing 1000 students, and are meant to supplement and support in-person library instruction. It is our hope 
that not only will these learning modules assist in developing student information literacy, but the increased visibility of the library might make students more willing to seek help when they need it. The discussion forum included in the CMS is being monitored by a librarian and it is hoped that any information literacy issues arising can be dealt with on the site and immediately shared with all students. While this cuts down on the live face-to-face time that these students will have with the librarian, they will still have the more advanced concepts delivered live via Skype, so not all personal connection will be lost. There will be marked exercises and quizzes as part of the pre-recorded modules to ensure the students will complete them. The librarian will still be available to answer any questions that the students may have encountered during the online portion of the lesson, as well as addressing more complex research instruction.

One way to prepare to meet the needs of students when they do reach out to us is to become more familiar with the library resources that are available in Edmonton and Calgary at other institutions. Caspers (2000) found that even when the home institution (i.e. U of L) provided excellent services, distance students have a tendency to use their local libraries. Our distance students are concentrated in two locations which makes it feasible for our staff to familiarize ourselves with local resources. Each of these cities has at least two universities in addition to colleges and technical institutes. While students may not have the full range of local service available to them, they should be able to access databases at these libraries in person and borrow material using their TAL or COPPUL library cards.

\section{Conclusion}


Information literacy is an essential skill both for a successful academic career and for a professional in the information age. Simply providing students with access to information sources is not enough to meet their immediate research needs or their long term information literacy needs. While in-person assistance might be the ideal solution for some, it is not always a realistic possibility. In addition, the very nature of distance education often means classes and studies occur at odd hours. In order to provide effective support to distance learners, librarians need to be creative and find unique solutions. The University of Lethbridge Library faced the challenge of trying to provide services and support to students at two satellite campuses that were not anticipated to be long-term or to expand to their current enrolment levels. Our fiscal realities and existing staff complement do not allow for a dedicated in-person librarian; however, valuing the importance of a human connection, the use of Skype has provided us with a reasonable method of providing personal assistance and support. We hope to expand the use of this technology in the future by offering individual research consultations via Skype. In addition, the development of short instructional videos on a variety of research topics for all Writing 1000 students should provide distance students with just-in-time access to essential information, while decreasing the reliance on Skype as the only method of instruction and alleviating technological difficulties of 'live' instruction. Finally, we shall continue to innovate and seek new technologies and opportunities to provide the best library service possible to students regardless of their location. 


\section{References}

Adolphus, M. (2009), "Using the web to teach information literacy”, Online, Vol. 33 No. 4, pp. 21-25.

Anderson, K. and May, F. A. (2010), "Does the method of instruction matter? An experimental examination of information literacy instruction in the online, blended and face-to-face classrooms", The Journal of Academic Librarianship, Vol. 36 No.6, pp.494-500.

Arthur, L. and Tait, A. (2004), “Too little time to learn? Issues and challenges for those in work." Studies in the Education of Adults, Vol. 36 No. 20, pp. 222-234.

Association of College and Research Libraries. (2000), Information Literacy Competency Standards for Higher Education. Chicago: American Library Association. available at: http://www.ala.org/ala/mgrps/divs/acrl/standards/standards.pdf (accessed 12 November 2010).

Association of College and Research Libraries. (2008), Standards for distance learning library services. available at:

http://www.ala.org/ala/mgrps/divs/acrl/standards/guidelinesdistancelearning.cfm (accessed 9 January 2011).

Association of Universities and Colleges of Canada. (2007), Trends in higher education. available at: http://www.aucc.ca/_pdf/english/publications/trends_2007_vol1_e.pdf (accessed 10 May 2011)

Barnhart, A. C. and Stanfield A. G. (2011), "When coming to campus is not an option: using web conferencing to deliver library instruction", Reference Services Review, Vol.39 No. 1, pp. 58-65. 
Booth, C. (2008), "Developing Skype-Based Reference services”, Internet Reference Services Quarterly Vol. 13 No. 2, pp.147-165.

Burkhardt, J. M., Kinnie, J., and Cournoyer, C. M. (2008), “Information literacy successes compared: Online vs. face to face”, Journal of Library Administration, Vol. 48 No. 3, pp. 379-389.

Caspers, J. S. (2000), “Outreach to distance learners: When the distance education instructor sends students to the library, where do they go?” Arant, W. and Mosley, P. A. (Eds.), Library outreach, partnerships, and distance education: Reference librarians on the gateway. Haworth Press, New York, pp. 299-311.

Gibson, C. (2008), “The History of Information Literacy”, Cox, C. N. (Ed.), Information literacy instruction handbook, Chicago, Association of College and Research Libraries, pp. 1025.

Herring, S. D., Burkhardt, R. R. and Wolfe, J. L. (2009), "Reaching remote students: Athens State University's electronically embedded librarian program", College and Research Library News, Vol. 70 No. 11, pp. 630-633.

Hines, S. S. (2008), “How it’s done: Examining distance education library instruction and assessment", Journal of Library Administration, Vol. 48 No. 3/4, pp. 567-478.

Holman, L. (2000), “A comparison of computer-assisted instruction and classroom bibliographic instruction”, Reference \& User Services Quarterly, Vol. 40 No.1, pp. 53-60.

Institutional Analysis University of Lethbridge. (2011).

Jayne, E. A. (2000), “The librarian as bricoleur: Meetings the needs of distance learners”, Sarkodie-Mensah, K. (Ed.), References services for the adult learner: challenging issues for the traditional and technological era, New York, Haworth Press, pp. 161-170. 
Messner, K. (2010). “An author in every classroom”, School Library Journal, Vol. 56 No. 9 , pp.42-44.

Murphy, A. and Crosser, R. (2010), "Solving self-regulated learner issues”, Strategic Finance, Vol. 91 No. 9, pp.19-20.

Newton, R. (2007), “Developing information literate off-campus learners: pedagogical issues and current practice", Libri, Vol.57 No.2, pp.140-164.

Oud, J. (2009), “Guidelines for effective online instruction using multimedia screen casts”, Reference Services Review, Vol. 37 No. 2, pp.164-177.

Owens, R. and Bozeman, D. (2009), “Toward a faculty-librarian collaboration: Enhancement of online teaching and learning", Journal of Library \& Information Science, Vol. 3, pp. 3138.

Pastula, M. (2010), "Use of information and communication technology to enhance the information literacy skills of distance students", Journal of Library \& Information Services in Distance Learning, Vol. 4 No.3, pp. 77.

Pollack, T. A. (1998), "Preparing a course for distance education deliver,” Paper presented at Association of Small Computer Users in Education: Proceedings of the ASCUE Summer Conference, June 1998, North Myrtle Beach, South Carolina.

Raraigh-Hopper, J. (2009), “Improving library services for distance learners: A literature review", The Reference Librarian, Vol. 51 No,1, pp. 69-78.

Reid, S. (2009), “Online courses and how they change the nature of class", First Monday Vol. 3 No.2, pp. 1-15. available at: http://firstmonday.org/htbin/cgiwrap/bin/ojs/index.php/fm/article/view/2167/2114 (accessed 3 February 2011). 
Rosen, J. (2009), “To Skype or not to Skype?” Publisher's Weekly Vol. 56 No. 50 pp. 22-23.

Secker, J. D. (2007), The information literacy cookbook: ingredients, recipes and tips for success. Chandos, Oxford.

Signorelli, P. (2008), "Skype as a conference tool”, American Libraries Vol. 38 No. 5 pp.32. University of Lethbridge. (2010a), Facts book 2009-2010. available at: http://www.uleth.ca/analysis/sites/analysis/files/2009-10\%20facts\%20book_v7_web.pdf (accessed 20 February 2011).

University of Lethbridge. (2010b). Undergraduate university calendar. available at: http://www.uleth.ca/ross/calendar/cal_doc.pdf (accessed 5 February 2011).

Veal, R. E. (2000), “Understanding the characteristics, concerns and priorities of adult learners to enhance library services to them," Sarkodie-Mensah, K. (Ed.), References services for the adult learner: challenging issues for the traditional and technological era. Haworth Press, New York, pp. 113-118.

Whitehurst, A. P. and Willis, C. N. (2009), "Building collaborative reference and instructional services for distance education students", Southeastern Librarian, Vol. 57 No.1, pp. 2027.

Wilson, V. (1994), "Developing the adult independent learner: Information literacy and the remote external student”, Distance Education, Vol. 15 No. 2, pp. 254-278. 